\title{
Atrial fibrillation and risks of cardiovascular disease, renal disease, and death: systematic review and meta-analysis
}

\author{
Ayodele Odutayo, ${ }^{1}$ Christopher X Wong, ${ }^{2}$ Allan J Hsiao, ${ }^{3}$ Sally Hopewell, ${ }^{1}$ Douglas G Altman, ${ }^{1}$ \\ Connor A Emdin ${ }^{4}$
}

${ }^{1}$ Centre for Statistics in

Medicine, Nuffield Department

of Orthopaedics, Rheumatology

and Musculoskeletal Sciences,

University of Oxford, Oxford, UK

${ }^{2}$ Nuffield Department of

Population Health, University of

Oxford, Oxford, UK

${ }^{3}$ Department of Economics,

Massachusetts Institute of

Technology, Cambridge, MA, USA

4St John's College, University of

Oxford, Oxford, UK

Correspondence to: A Odutayo ayodele.odutayo@bnc.ox.ac.uk Additional material is published online only. To view please visit the journal online.

Cite this as: BMJ 2016;354:i4482 http://dx.doi.org/10.1136/bmj.i4482

Accepted: 10 August 2016

\section{ABSTRACT}

OBJECTIVE

To quantify the association between atrial fibrillation and cardiovascular disease, renal disease, and death. DESIGN

Systematic review and meta-analysis.

\section{DATA SOURCES}

Medline and Embase.

\section{ELIGIBILITY CRITERIA}

Cohort studies examining the association between atrial fibrillation and cardiovascular disease, renal disease, and death. Two reviewers independently extracted study characteristics and the relative risk of outcomes associated with atrial fibrillation: specifically, all cause mortality, cardiovascular mortality, major cardiovascular events, any stroke, ischaemic stroke, haemorrhagic stroke, ischaemic heart disease, sudden cardiac death, congestive heart failure, chronic kidney disease, and peripheral arterial disease. Estimates were pooled with inverse variance weighted random effects meta-analysis.

\section{RESULTS}

104 eligible cohort studies involving 9686513 participants (587 867 with atrial fibrillation) were identified. Atrial fibrillation was associated with an increased risk of all cause mortality (relative risk 1.46, $95 \%$ confidence interval 1.39 to 1.54$)$, cardiovascular mortality $(2.03,1.79$ to 2.30$)$, major cardiovascular events $(1.96,1.53$ to 2.51$)$, stroke $(2.42,2.17$ to 2.71$)$, ischaemic stroke $(2.33,1.84$ to 2.94$)$, ischaemic heart disease $(1.61,1.38$ to 1.87$)$, sudden cardiac death (1.88, 1.36 to 2.60$)$, heart failure $(4.99,3.04$ to 8.22$)$, chronic kidney disease $(1.64,1.41$ to 1.91$)$, and peripheral arterial disease $(1.31,1.19$ to 1.45$)$ but not haemorrhagic stroke $(2.00,0.67$ to 5.96$)$. Among the outcomes

\section{WHAT IS ALREADY KNOWN ON THIS TOPIC}

Atrial fibrillation is associated with an increased risk of all cause mortality and stroke, as well as higher medical costs and a reduced quality of life

The association between atrial fibrillation and cardiovascular outcomes other than stroke is less clear

\section{WHAT THIS STUDY ADDS}

Atrial fibrillation is associated with a wide range of cardiovascular events, including cardiovascular mortality, major cardiovascular events, heart failure, ischaemic

heart disease, chronic kidney disease, and sudden cardiac death, as well as stroke and all cause mortality

The relative and absolute risk increase associated with many of these events is greater than that of stroke

Interventions are needed to reduce the risk of non-stroke cardiovascular outcomes in adults with atrial fibrillation

examined, the highest absolute risk increase was for heart failure. Associations between atrial fibrillation and included outcomes were broadly consistent across subgroups and in sensitivity analyses.

\section{CONCLUSIONS}

Atrial fibrillation is associated with an increased risk of death and an increased risk of cardiovascular and renal disease. Interventions aimed at reducing outcomes beyond stroke are warranted in patients with atrial fibrillation.

\section{Introduction}

Atrial fibrillation is a leading cause of morbidity and mortality, with an estimated five million incident cases globally. ${ }^{1}$ It is increasing in prevalence in both developing and developed countries and is associated with an increased risk of all cause mortality and stroke, as well as higher medical costs and a reduced quality of life. ${ }^{23}$

Although the prevention and management of stroke in atrial fibrillation has been the primary focus of guidelines ${ }^{4}$ and clinical trials, ${ }^{56}$ recent studies have suggested that it can also be associated with a range of different cardiovascular diseases, including ischaemic heart disease and chronic kidney disease. ${ }^{27-10}$ Individual studies, however, have provided conflicting estimates of the strength of the association between atrial fibrillation and a range of cardiovascular diseases and have not agreed on whether there are relevant associations at all, possibly because of the small sample sizes examined.11-14 Pooling all available evidence could allow for the determination of robust estimates of any associations that could inform outcome selection in future randomised controlled trials and guide public health efforts to reduce the incidence of associated cardiovascular disease.

We conducted a systematic review and meta-analysis of the association between atrial fibrillation and cardiovascular disease and death to determine the relative and absolute risks of death and a range of associated cardiovascular outcomes. We also examined whether associations differed by important patient characteristics, including age, the presence of cardiovascular disease, and baseline risk.

\section{Methods}

This study was conducted in accordance with the Meta-analysis of Observational Studies in Epidemiology (MOOSE) guidelines ${ }^{15}$ and the Preferred Reporting Items for Systematic Reviews and Meta-Analyses (PRISMA) guidelines. ${ }^{16}$

\section{Data sources and searches}

We conducted a systematic search of Medline and Embase (inception to June 2016). A qualified research 
librarian developed the search strategy (see table A in appendix). This was supplemented by a review of references of included studies and review articles.

\section{Study selection criteria}

We included cohort studies of adults with and without atrial fibrillation that reported a measure of relative risk for death or cardiovascular disease (described below) and a corresponding measure of variability. To avoid overestimating the association between atrial fibrillation and our outcomes of interest, we required studies to include a minimum of 50 participants with atrial fibrillation and 50 participants without. Studies were also required to have at least six months' mean/median follow-up because we sought to assess the mid to long term risks associated with atrial fibrillation. No language restrictions were applied, and non-English studies were translated by $\mathrm{AJH}$, who has extensive experience in translating epidemiological studies.

\section{Data extraction and quality assessment}

Two reviewers (AO and CAE) independently reviewed titles and abstracts to assess studies for their inclusion. Three reviewers (AO, CXW, CAE) independently abstracted data using standardised forms. When available, we abstracted information on general study characteristics (study name or investigator's name, recruitment period, median duration of follow-up, year of publication of the primary findings), number of participants with and without atrial fibrillation, mean age, number of men, and relative risk of outcomes.

We abstracted relative risk estimates and associated 95\% confidence intervals for the association between atrial fibrillation and all cause mortality, cardiovascular mortality, major cardiovascular events (a composite of cardiovascular death, fatal and non-fatal stroke, ischaemic heart disease, and congestive heart failure), and disease specific events: fatal and non-fatal stroke (all stroke or a stroke subtype if all stroke was not provided), fatal and non-fatal haemorrhagic stroke, fatal and non-fatal ischaemic stroke, ischaemic heart disease events (a composite of ischaemic heart disease death and non-fatal myocardial infarction), incident development of congestive heart failure, chronic kidney disease, and peripheral arterial disease. Maximally adjusted relative risk estimates were abstracted, along with the list of covariates included in the published multivariable regression model. Studies that did not report the variables that were adjusted for were excluded. One study that reported the development of end stage renal disease was included in the meta-analysis of chronic kidney disease. ${ }^{10}$

Studies were categorised as unadjusted, adequately adjusted, or well adjusted. Unadjusted studies did not adjust for any confounders and were excluded. Adequately adjusted studies adjusted for, at a minimum, sex, age, and the presence of baseline cardiovascular disease. Well adjusted studies also adjusted for at least two established cardiovascular risk factors-blood pressure, cholesterol, smoking status, and diabetes. We chose these risk factors because they are important contributors to each of the outcomes examined in our study. Studies that did not report the covariates included in their regression model were also excluded because we could not determine whether they properly adjusted for important cofounders and thus whether they fulfilled the prespecified inclusion criteria of this meta-analysis. In our sensitivity analysis we stratified studies based on the level of adjustment.

We assessed risk of bias using the Newcastle-Ottawa scale, ${ }^{17}$ which assesses studies on three broad domains: the selection of participants for study groups; the comparability of study groups; and the ascertainment of the outcome. A star rating system is used and the maximum numbers of stars achievable are: selection (four stars), comparability (two), and outcome (cohort studies only; three stars). We applied strict criteria to assess comparability (of individuals with or without atrial fibrillation) based on which variables were included in the multivariable models. To receive one star for comparability, studies were required to meet the aforementioned criteria for adequate adjustment. To receive two stars, studies were required to meet the criteria for being well adjusted. Finally, studies were considered at low risk of bias if they achieved a full rating in at least two categories of selection, comparability, or outcome assessment.

\section{Statistical analysis}

For all analyses, we calculated overall summary estimates using inverse variance weighted random effects meta-analysis. For studies that reported separate relative risk estimates for subgroups (for example, different age groups, men versus women), we first used inverse variance weighted fixed effects meta-analysis to generate overall study level relative risks before random effects meta-analysis. Individual relative risk estimates and summary estimates were displayed graphically with forest plots. Heterogeneity was quantified with the $\mathrm{I}^{2}$ statistic and the $\mathrm{Q}$ test.

We calculated the absolute risk increase for each vascular outcome associated with atrial fibrillation by multiplying summary relative risks by the incidence rate of each outcome of interest. Specifically, ARI= $(\mathrm{RR}-1) \times(\mathrm{ACR})$ where ARI is the absolute risk increase, $\mathrm{RR}$ is the relative risk, and ACR is the assumed control risk. As the US contributed the largest share of studies in our analysis, we used American Heart Association estimates of the incidence of cardiovascular mortality, ischaemic heart disease, heart failure, sudden cardiac death, and stroke. ${ }^{18}$ We used Centers for Disease Control and Prevention estimates of the incidence of all cause mortality ${ }^{19}$ and chronic kidney disease. ${ }^{20}$ Absolute risk increases were expressed in events per 1000 participant years of follow-up. As we could not obtain an estimate for the incidence of major cardiovascular events in the US general population, we have not provided an absolute risk increase associated with atrial fibrillation for major cardiovascular events.

\section{Stratified analyses and sensitivity analyses}

To include a sufficient number of studies in each stratum, we restricted stratified and sensitivity analyses to 
outcomes with nine or more studies (all cause mortality, cardiovascular mortality, major cardiovascular events, ischaemic heart disease, stroke, and ischaemic stroke). We conducted four stratified analyses to examine whether relative risks of outcomes were influenced by patients' characteristics. We divided studies into thirds by the proportion of participants with a history of ischaemic heart disease at baseline, the proportion of participants with a history of stroke at baseline, mean age, and absolute risk of death and cardiovascular disease (in events per 1000 patient years of follow-up). We tested for trend in these stratified analyses using random effects meta-regression. We did not examine whether relative risks were influenced by type of atrial fibrillation (chronic versus paroxysmal) as there were fewer than nine studies that reported on type for any given outcome of interest (table $\mathrm{B}$ in appendix).

We conducted six sensitivity analyses to examine whether heterogeneity between studies was caused by differences in study characteristics. We stratified studies by type of population (general population-for example, a community based cohort study-versus specific population-for example, a cohort study of individuals with a history of stroke), year of publication, duration of follow-up, region of study conduct (Asia, Europe, US, international, other), method of ascertainment of atrial fibrillation (electrocardiography only, electrocardiography and medical records, and medical records only), and level of adjustment for confounders (adequately adjusted $v$ well adjusted).

We used a sequential exclusion strategy, as described by Patsopoulos and colleagues, to examine whether overall estimates were influenced by the substantial heterogeneity observed. ${ }^{21}$ We sequentially and cumulatively excluded studies that accounted for the largest share of heterogeneity until $\mathrm{I}^{2}$ was less than $50 \%$. We then examined whether relative risk estimates were consistent. In accordance with Cochrane, evidence of publication bias was examined through funnel plots if there were more than 10 available studies. ${ }^{22}$ Funnel plot asymmetry was further confirmed with Egger's test. ${ }^{23}$ If asymmetry was present, we used the trim-and-fill method to adjust for publication bias. ${ }^{24}$

\section{Patient involvement}

No patients were involved in setting the research question or the outcome measures, nor were they involved in developing plans for design or implementation of the study. No patients were asked to advise on interpretation or writing up of results. There are no plans to disseminate the results of the research to study participants or the relevant patient community.

\section{Results}

We reviewed 4100 studies and excluded 3836 in the abstract screen. After we reviewed 264 full text articles, we excluded a further 160 (fig 1). We therefore included 104 studies involving 9686513 patients in our meta-analysis. Of these individuals, 587867 (6.1\%) had atrial fibrillation. Five studies did not specify the method of ascertainment. Although outcome definitions were broadly consistent, the criteria applied in large prospective studies and secondary analyses of randomised trials were often more detailed than the criteria applied in studies that were strictly reliant on administrative datasets. Based on the Newcastle Ottawa scale, 67 studies were judged to be at low risk of bias, and 69 provided estimates from well adjusted regression models. Detailed general characteristics of the included studies as well as the adjustments applied in regression models, outcome definitions, and risk of bias assessment are provided in tables B-E in the appendix.

\section{All cause mortality}

Sixty four studies ${ }^{211} 121425-86$ involving 1009501 patients examined all cause mortality as an outcome. There were $149746(14.8 \%)$ adults with atrial fibrillation, and the prevalence ranged from $0.2 \%$ to $56.3 \%$. The median follow-up was 3.1 years (interquartile range 1-5.9). The pooled relative risk was 1.46 (95\% confidence interval 1.39 to 1.53; figs 2 and 3). Marked heterogeneity was observed $\left(\mathrm{I}^{2}=93 \%, \mathrm{P}<0.001\right)$. The corresponding absolute risk increase in all cause mortality associated with atrial fibrillation, based on the US population, was 3.8 events/1000 participant years (3.2 to 4.4). In subgroup analyses, studies were separated into thirds based on the proportion of adults with a history of ischaemic heart disease, the proportion with a history of stroke, mean participant age, and baseline absolute risk of all cause mortality. Relative risks of all cause mortality were consistent across all subgroups $(\mathrm{P} \geq 0.2$ for trend, fig 4).

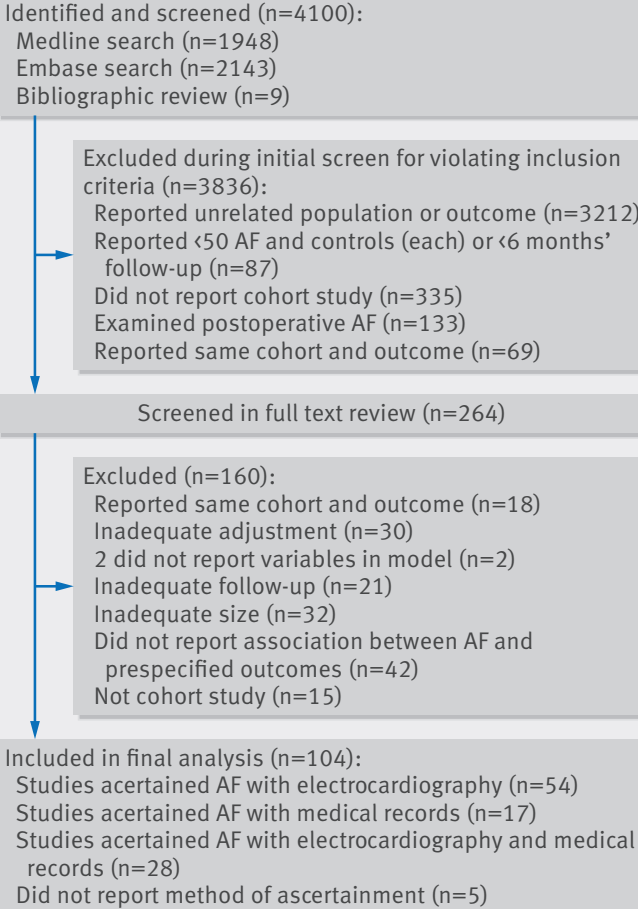

Did not report method of ascertainment $(n=5)$

Fig 1 | Identification of studies included in review of atrial fibrillation (AF) and risks of cardiovascular disease, renal disease, and death 


\begin{tabular}{|c|c|c|c|c|}
\hline Outcome & Studies & Relative risk $(95 \% \mathrm{Cl})$ & Relative risk $(95 \% \mathrm{Cl})$ & $I^{2}(\%)$ \\
\hline Peripheral arterial disease & 1 & $\Rightarrow$ & 1.31 (1.19 to 1.45$)$ & NA \\
\hline All cause mortality & 66 & - & $1.46(1.39$ to 1.53$)$ & 93 \\
\hline Ischaemic heart disease & 16 & $\rightarrow-$ & 1.61 (1.38 to 1.87$)$ & 86 \\
\hline Chronic kidney disease & 3 & $\rightarrow$ & 1.64 (1.41 to 1.91$)$ & 50 \\
\hline Sudden cardiac death & 7 & & 1.88 (1.36 to 2.60$)$ & 78 \\
\hline Major cardiovascular events & s 9 & . & $1.96(1.53$ to 2.51$)$ & 98 \\
\hline Haemorrhagic stroke & 3 & & $2.00(0.67$ to 5.96$)$ & 73 \\
\hline Cardiovascular mortality & 14 & $\rightarrow-$ & 2.03 (1.79 to 2.30$)$ & 76 \\
\hline Ischaemic stroke & 12 & $\longrightarrow$ & $2.33(1.84$ to 2.94$)$ & 87 \\
\hline Stroke & 38 & $\rightarrow$ & $2.42(2.17$ to 2.71$)$ & 96 \\
\hline \multirow[t]{2}{*}{ Heart failure } & 6 & & 4.99 (3.04 to 8.22) & 93 \\
\hline & 0.5 & 2 & & \\
\hline
\end{tabular}

Fig 2 Association between atrial fibrillation and all cause mortality and cardiovascular and renal disease, showing summary relative risks for each outcome examined. $N A=$ not available

Cardiovascular mortality and major cardiovascular events

Fourteen studies 211326166687075777881828788 involving 342453 patients examined cardiovascular mortality as an outcome. There were 17167 (5.0\%) adults with atrial fibrillation, and the prevalence ranged from $0.2 \%$ to $56.3 \%$. The median follow-up was 4.9 years (interquartile range 2.8-11.4). The pooled relative risk was 2.03 (95\% confidence interval 1.79 to 2.30; fig 2 and fig A in appendix). The absolute risk increase in cardiovascular mortality associated with atrial fibrillation was 2.6 events/1000 participant years (2.0 to 3.3). Nine studies $^{2314152687188-90}$ involving 2467017 patients examined major cardiovascular events as an outcome. There were $21707(0.9 \%)$ adults with atrial fibrillation, and the prevalence ranged from $0.5 \%$ to $29.7 \%$. The median follow-up was 4.4 years (4.0 to 10.1). Overall, atrial fibrillation was associated a $96 \%$ higher risk of major cardiovascular events (relative risk 1.96, 1.53 to 2.51; fig 2 and fig B in appendix).

Both analyses showed considerable heterogeneity $\left(\mathrm{I}^{2}=76 \%\right.$ and $\mathrm{P}<0.001$ for cardiovascular mortality and $\mathrm{I}^{2}=98 \%$ and $\mathrm{P}<0.001$ for major cardiovascular events). In subgroup analyses, the relative risk of cardiovascular mortality was lower with increasing age $(\mathrm{P}=0.05$, fig $\mathrm{C}$ in appendix), and the relative risk of major cardiovascular events declined when we stratified studies based on the absolute event rate in their control group $(\mathrm{P}=0.03$, fig D in appendix). Pooled relative risks for both outcomes were consistent for other subgroups examined (figs C and $\mathrm{D}$ in appendix).

\section{Stroke}

Thirty eight studies $231334248526168707177788182878891-112$ involving 6143925 patients reported results for any stroke. There were $430600(7.0 \%)$ adults with atrial fibrillation, and the prevalence ranged from $0.2 \%$ to $50.7 \%$. The median follow-up was 4.2 years (interquartile range 1.7-8.0). The pooled relative risk was 2.42 (95\% confidence interval 2.17 to 2.71; figs 2 and 5). There was considerable heterogeneity $\left(\mathrm{I}^{2}=96 \%, \mathrm{P}<0.001\right)$. The association between atrial fibrillation and stroke was consistent, irrespective of baseline demographics and clinical characteristics (fig E in appendix). The absolute risk increase of stroke associated with atrial fibrillation was 3.6 events/1000 participant years (3.0 to 4.3).

Twelve studies 365159689192100101103107111113 specifically reported results for ischaemic stroke. The pooled relative risk estimate was 2.33 (95\% confidence interval 1.84 to $2.94)$, and there was considerable heterogeneity $\left(\mathrm{I}^{2}=87 \%\right.$, $\mathrm{P}<0.001$; fig 2 and fig $\mathrm{F}$ in appendix). The relation between atrial fibrillation and ischaemic stroke was consistent, irrespective of baseline demographics and clinical characteristics (fig $\mathrm{G}$ in appendix). The absolute risk increase for ischaemic stroke was 2.9 events/1000 participant years (1.9 to 4.3). Three studies ${ }^{691107}$ reported results for haemorrhagic stroke. Atrial fibrillation was not associated with a higher risk of haemorrhagic stroke, although the confidence interval was wide (relative risk 2.00, 0.67 to 5.96; fig 2 and fig $\mathrm{H}$ in appendix).

Ischaemic heart disease and sudden cardiac death Sixteen studies 2813144248525461666878828588101 involving 395957 patients examined ischaemic heart disease as an outcome (figs 2 and 6). There were 30977 (7.8\%) adults with atrial fibrillation, and the prevalence ranged from $0.2 \%$ to $56.3 \%$. The median follow-up was 4.1 years (interquartile range 3.2-8.3). The pooled relative risk was 1.61 (95\% confidence interval 1.38 to 1.87 ). There was considerable heterogeneity $\left(\mathrm{I}^{2}=86 \%\right.$, $\mathrm{P}<0.001)$. The absolute risk increase for ischaemic heart disease was 1.4 events/1000 participant years (0.9 to 2). The pooled relative risk for ischaemic heart disease was consistent across subgroups of baseline cardiovascular disease, age, and baseline risk (fig I in appendix).

Seven studies ${ }^{13455485114-116}$ involving 48694 patients examined sudden cardiac death as an outcome. There were 6061 (12.4\%) adults with atrial fibrillation, and the prevalence ranged from $0.6 \%$ to $28.9 \%$. The median follow-up was 3.0 years (interquartile range 2.8-4.4). The pooled relative risk of sudden cardiac death was 1.88 (95\% confidence interval 1.36 to 2.60 ; fig J in appendix). Though there was considerable heterogeneity $\left(\mathrm{I}^{2}=78 \%\right.$, $\mathrm{P}<0.001)$, we did not perform sensitivity analyses because of the small number of studies. The absolute risk increase in sudden cardiac death was 0.6 events/1000 participant years (0.2 to 1.1).

\section{Congestive heart failure}

Six studies 24271101117118 involving 82476 patients examined incident congestive heart failure as an outcome. There were 11677 (14.2\%) adults with atrial fibrillation, and the prevalence ranged from $0.6 \%$ to $43.2 \%$. The median follow-up was 5.4 years (interquartile range 3.6-15.4). The pooled relative risk of incident congestive heart failure was 4.99 (95\% confidence interval 3.04 to 8.22; fig 2 and fig $\mathrm{K}$ in appendix). Though there was considerable heterogeneity $\left(\mathrm{I}^{2}=93 \%, \mathrm{P}<0.001\right)$, we did not perform sensitivity analyses because of the small number of studies. The absolute risk increase in incident congestive heart failure associated with atrial fibrillation was 11.1 (5.7 to 20) events/1000 participant years. 


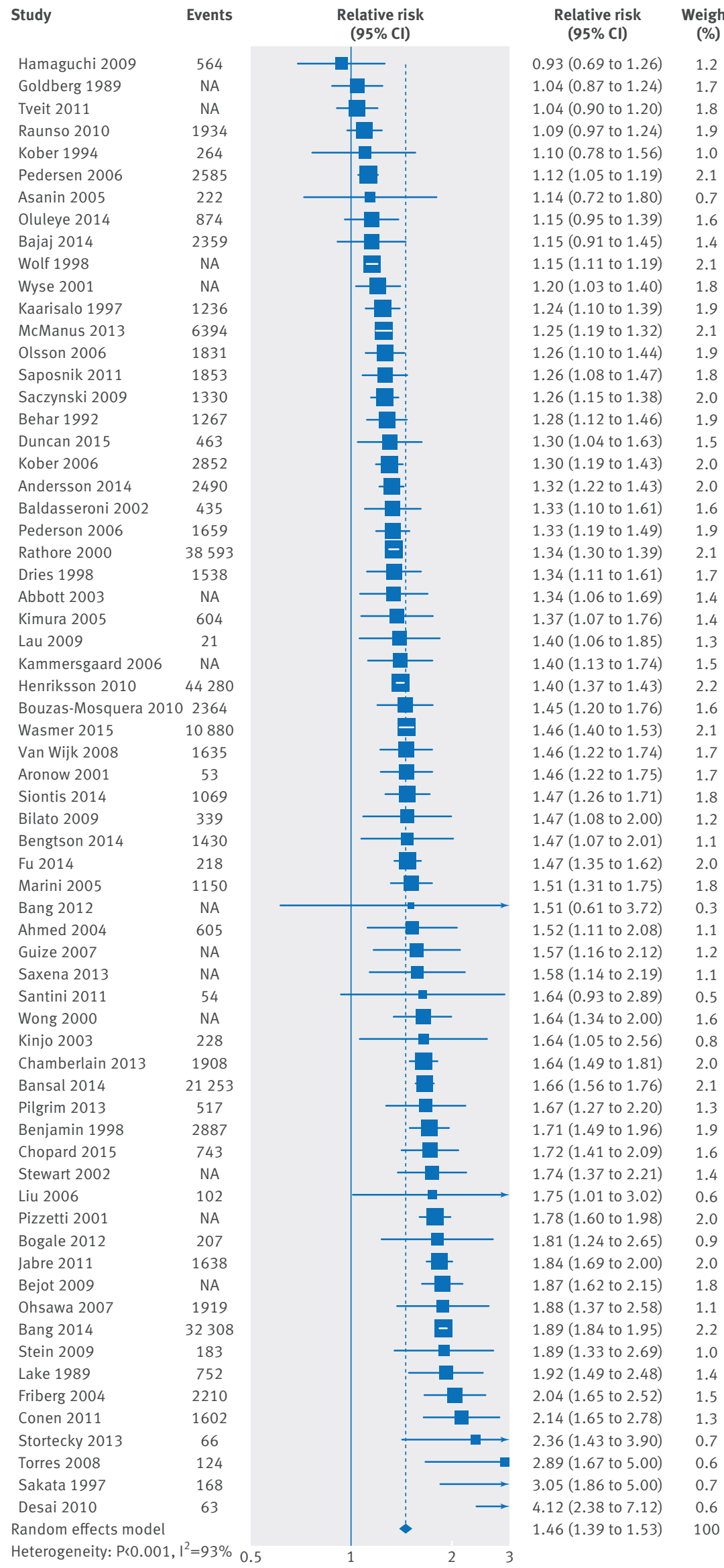

Fig 3 Association between atrial fibrillation and all cause mortality. NA=not available

\section{Chronic kidney disease and peripheral arterial disease}

Three studies ${ }^{10119120}$ involving 467000 patients examined chronic kidney disease as an outcome. There were $20312(4.3 \%)$ adults with atrial fibrillation, and the prevalence ranged from $0.7 \%$ to $8.6 \%$. The median follow-up was 5.9 years (interquartile range 5.1-6.7). The pooled relative risk of chronic kidney disease was 1.64 (95\% confidence interval 1.41 to 1.91; fig L in appendix). Heterogeneity was non-significant $\left(\mathrm{I}^{2}=50 \%, \mathrm{P}=0.14\right)$. The absolute risk increase in chronic kidney disease associated with atrial fibrillation was 6.6 (4.3 to 9.4) events/1000 participant years.

Only one study ${ }^{121}$ examined the association between atrial fibrillation and peripheral arterial disease. The relative risk was 1.31 (95\% confidence interval 1.19 to 1.45) was reported.

\section{Sensitivity analyses}

In sensitivity analyses of study characteristics, stratified by type of population, method of ascertainment of atrial fibrillation, level of adjustment, year of publication, median follow-up, proportion receiving anticoagulation, and location, the relative risks of outcomes were broadly consistent across strata. The relative risk of all cause mortality was lower in studies with a higher proportion of participants receiving anticoagulation (table $\mathrm{F}$ in appendix). No interaction was otherwise observed for all cause mortality and for cardiovascular mortality for any subgroups ( $\mathrm{P}>0.05$ for interaction/ trend; tables $\mathrm{F}$ and $\mathrm{G}$ in appendix). High levels of heterogeneity $\left(\mathrm{I}^{2}>75 \%\right)$ continued to be observed in most sensitivity analyses. There was a stronger relative risk of major cardiovascular events associated with atrial fibrillation in studies conducted in a general population than a specific population (relative risk 2.71 (95\% confidence interval 1.82 to 4.04) $v 1.39$ (1.18 to 1.63), respectively; $\mathrm{P}=0.002$ for interaction; table $\mathrm{H}$ in appendix). Although a significant test result for interaction for major cardiovascular events by location was also observed, this was because of a single study that was conducted in the US. We found no other significant interactions for major cardiovascular events $(\mathrm{P}>0.05$ for interaction/trend, table $\mathrm{H}$ in appendix) and no interactions for stroke for any subgroups, including those based on the proportion of adults with atrial fibrillation receiving anticoagulation (table I in appendix). Relative risks of ischaemic stroke and ischaemic heart disease were stronger in studies conducted in general populations than in studies conducted in specific populations ( $\mathrm{P}<0.05$ for interaction, tables $\mathrm{J}$ and $\mathrm{K}$ in appendix). Relative risks of ischaemic stroke and ischaemic heart disease were also larger in studies with a longer follow-up ( $\mathrm{P}=0.04$ and 0.01 , respectively, for trend, tables J and $\mathrm{K}$ in appendix). The relative risk of ischaemic stroke did not vary based on proportion of adults with atrial fibrillation receiving anticoagulation.

When we sequentially excluded studies contributing the largest amount to heterogeneity until $\mathrm{I}^{2}$ was less than $50 \%$, pooled relative risks for outcomes were similar to the original estimates (table L in appendix). Atrial 


\begin{tabular}{|c|c|c|c|c|c|}
\hline Outcome & Studies & $\begin{array}{l}\text { Relative risk }(95 \% \mathrm{Cl}) \\
\text { of all cause mortality }\end{array}$ & $\begin{array}{l}\text { Relative risk }(95 \% \mathrm{Cl}) \\
\text { of all cause mortality }\end{array}$ & $I^{2}(\%)$ & $\begin{array}{c}P \\
\text { trend }\end{array}$ \\
\hline 43- 64 & 18 & $\rightarrow$ & 1.51 (1.38 to 1.66$)$ & 67 & \\
\hline$>64-71$ & 20 & $\rightarrow$ & 1.43 (1.29 to 1.59$)$ & 94 & 0.44 \\
\hline$>71-86$ & 24 & 一 & $1.42(1.34$ to 1.50$)$ & 88 & \\
\hline \multicolumn{6}{|c|}{ Coronary heart disease } \\
\hline $0-0.225$ & 16 & $t$ & $1.56(1.42$ to 1.71$)$ & 87 & \\
\hline$>0.225-0.722$ & 19 & + & $1.37(1.25$ to 1.50$)$ & 84 & 0.76 \\
\hline$>0.722-1$ & 21 & $\rightarrow-$ & 1.47 (1.33 to 1.63$)$ & 95 & \\
\hline \multicolumn{6}{|c|}{ Risk (events/1000 patient years) } \\
\hline $3-60.9$ & 18 & $\rightarrow$ & 1.61 (1.46 to 1.78$)$ & 75 & \\
\hline$>60.9-105$ & 17 & $\rightarrow-$ & $1.37(1.22$ to 1.54$)$ & 96 & 0.25 \\
\hline$>105-469$ & 17 & 一 & $1.41(1.34$ to 1.48$)$ & 75 & \\
\hline \multicolumn{6}{|l|}{ Stroke } \\
\hline $0-0.0387$ & 8 & $\rightarrow$ & 1.67 (1.47 to 1.89$)$ & 65 & \\
\hline$>0.0387-0.116$ & 16 & $\rightarrow-$ & 1.48 (1.30 to 1.69$)$ & 93 & 0.53 \\
\hline$<0.116-1$ & 12 & & 1.38 (1.29 to 1.49$)$ & 77 & \\
\hline & 0.5 & 2 & 3 & & \\
\hline
\end{tabular}

Fig 4 | Association between atrial fibrillation and mortality, stratified by patient demographics and baseline clinical characteristics. Studies were divided into thirds based on mean age of participants, proportion of participants with history of ischaemic heart disease at baseline, absolute risk of death and cardiovascular disease (in events per 1000 patient years of follow-up), and proportion of participants with history of stroke at baseline. For absolute risk, thirds were 3-60.9 events/1000 patient years, >60.9-105 events/1000 patient years, and $>105-469$ events/1000 patient years outcomes beyond stroke. In a retrospective cohort study of Medicare beneficiaries, investigators showed that heart failure was the most common non-fatal cardiovascular event among adults with atrial fibrillation. ${ }^{122}$ Furthermore, in an analysis of the RE-LY trial, which was a trial in patients with atrial fibrillation, cardiac deathssudden cardiac death and progressive heart failureaccounted for $37.4 \%$ of all deaths, whereas deaths related to stroke and haemorrhage accounted for $9.8 \%$ of all deaths. ${ }^{123}$ In our study, the relative and absolute risk of incident congestive heart failure was the highest among all outcomes studied.

Furthermore, we observed that atrial fibrillation was associated with an increased risk of ischaemic heart disease, chronic kidney disease, and sudden cardiac death, even though some individual studies reported non-significant associations. Notably, although the relative associations between atrial fibrillation and these outcomes were comparable, the absolute risk increases for ischaemic heart disease (1.4 events per 1000 participant years) and chronic kidney disease (6.6 events) were several times larger than for sudden cardiac death (0.6 events) because of the lower baseline incidence of sudden cardiac death in the general population.

Our assessment of the consistency of relative risk estimates across demographic and clinical subgroups of participants is an important expansion on previous studies, many of which have limited their analysis to a single patient subgroup, such as those with ischaemic heart disease and congestive heart failure. ${ }^{124} \mathrm{We}$ observed that the association between atrial fibrillation and cardiovascular disease and death was generally consistent, irrespective of baseline history of ischaemic heart disease, baseline history of stroke, mean participant age, and baseline risk. There were, however, two notable exceptions. Firstly, relative risk estimates for general population studies were typically larger than estimates based on studies in specific settings. This could be related to the selection of the controls and the proportion of patients with atrial fibrillation receiving effective evidence based treatments. Secondly, the relative risk of all cause mortality was lower in studies with a higher proportion of participants receiving anticoagulation, but we did not observe a similar pattern for stroke. The absence of any association between the relative risk of stroke and the use of anticoagulation should be interpreted with caution because of the small number of studies included in this analysis. Furthermore, if warfarin is used, it is difficult to determine the effectiveness of anticoagulation without measurements of INR (international normalised ratio). Differences in the proportion of adults with a low INR would affect our stratified analyses for stroke.

While relative associations between atrial fibrillation and cardiovascular disease and death were generally similar across participant characteristics, absolute increases in risk associated with atrial fibrillation would be expected to be larger among individuals with a higher baseline risk of cardiovascular disease. These results therefore suggest that atrial fibrillation is associated with greater absolute increases in risk of
Comparison with previous individual studies

Our study adds to the growing literature on the association between atrial fibrillation and cardiovascular 


\begin{tabular}{|c|c|c|c|c|c|}
\hline \multirow{2}{*}{$\begin{array}{l}\text { Outcome } \\
\text { Stortecky } 2013\end{array}$} & \multirow{2}{*}{$\begin{array}{c}\text { Events } \\
17\end{array}$} & \multicolumn{2}{|c|}{ Relative risk $(95 \% \mathrm{Cl})$} & \multirow{2}{*}{$\begin{array}{c}\text { Relative risk }(95 \% \mathrm{Cl}) \\
0.67(0.23 \text { to } 1.96)\end{array}$} & \multirow{2}{*}{$\begin{array}{c}\mathbf{I}^{2}(\%) \\
1\end{array}$} \\
\hline & & $\longleftrightarrow$ & & & \\
\hline Chopard 2015 & 153 & & & 0.87 (0.59 to 1.29$)$ & 3 \\
\hline Lau 2009 & NA & & & 1.01 (0.21 to 4.82$)$ & $<1$ \\
\hline Wolf 1998 & NA & & - & 1.15 (1.11 to 1.19$)$ & 4 \\
\hline Wetmore 2013 & 2877 & & & 1.21 (1.03 to 1.42$)$ & 4 \\
\hline Lau 2014 & 241 & & & 1.35 (1.01 to 1.81$)$ & 3 \\
\hline Simons 1998 & NA & & & $1.58(0.91$ to 2.75$)$ & 2 \\
\hline Sampson 2007 & 463 & & & 1.61 (1.28 to 2.03$)$ & 3 \\
\hline Hippisley-Cox 2013 & 77578 & & 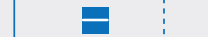 & 1.62 (1.51 to 1.73$)$ & 4 \\
\hline Biblo 2001 & NA & & & 1.64 (1.62 to 1.66$)$ & 4 \\
\hline Hillen 2003 & 153 & & & 1.70 (1.09 to 2.66$)$ & 3 \\
\hline Burke 2013 & 11229 & & - & 1.76 (1.65 to 1.88$)$ & 4 \\
\hline Soliman 2011 & 378 & & & 1.90 (1.10 to 3.28$)$ & 2 \\
\hline Manzano 2012 & 118 & & & $1.93(0.81$ to 4.58$)$ & 1 \\
\hline van Wijk 2008 & 518 & & & 1.94 (1.47 to 2.56$)$ & 3 \\
\hline Rodgers 2004 & NA & & & $2.03(1.31$ to 3.15$)$ & 3 \\
\hline Oluleye 2014 & 193 & & & $2.24(1.55$ to 3.24$)$ & 3 \\
\hline Bang 2014 & 5802 & & & 2.34 (2.13 to 2.58$)$ & 4 \\
\hline Andersson 2014 & 1426 & & & 2.58 (2.29 to 2.91$)$ & 4 \\
\hline Chao 2012 & 128 & & & 2.64 (1.67 to 4.18$)$ & 2 \\
\hline Guize 2007 & NA & & & 2.64 (1.27 to 5.51$)$ & 2 \\
\hline Ohsawa 2007 & 318 & & & 2.69 (1.42 to 5.10$)$ & 2 \\
\hline Stewart 2002 & 1316 & & & 2.76 (1.66 to 4.58$)$ & 2 \\
\hline Ruigomez 2009 & 273 & & & $3.00(2.27$ to 3.96$)$ & 3 \\
\hline Bishara 2011 & 74 & & & $3.03(1.73$ to 5.31$)$ & 2 \\
\hline Pilgrim 2013 & 47 & & & 3.08 (1.45 to 6.55$)$ & 1 \\
\hline Aronow 1999 & 510 & & & 3.18 (2.62 to 3.85$)$ & 4 \\
\hline Aronow 1996 & 434 & & & 3.34 (2.46 to 4.54$)$ & 3 \\
\hline Xu 2007 & 160 & & & $3.52(2.48$ to 5.00$)$ & 3 \\
\hline Wolf 1987 & 462 & & & 3.78 (2.80 to 5.09$)$ & 3 \\
\hline Friberg 2004 & 262 & & & $4.01(2.82$ to 5.70$)$ & 3 \\
\hline Iwahana 2011 & 405 & & & $4.11(2.28$ to 7.41$)$ & 2 \\
\hline Conen 2011 & 607 & & & $4.17(3.04$ to 5.71$)$ & 3 \\
\hline Wang 2013 & 5517 & & & $4.42(3.51$ to 5.56$)$ & 3 \\
\hline Hermann 2013 & 92 & & & $4.42(1.55$ to 12.60$)$ & 1 \\
\hline Kamel 2012 & 221 & & & $5.60(3.42$ to 9.16 & 2 \\
\hline Nakayama 1997 & 142 & & & 7.29 (3.83 to 13.86$)$ & 2 \\
\hline Feng 2009 & 214 & & & 15.93 (9.47 to 26.80$)$ & 2 \\
\hline Random effects mode & & & 1 & $2.42(2.17$ to 2.71$)$ & 100 \\
\hline Heterogeneity: $\mathrm{P}<0.0$ & $96 \%$ & 0.5 & 2 & & \\
\hline
\end{tabular}

Fig 5 Association between atrial fibrillation and stroke. $N A=$ not available

cardiovascular disease among individuals at high baseline risk and highlights the importance of risk stratification of participants with atrial fibrillation.

\section{Strengths and limitations}

The key strength of our study is its sample size. We were able to identify 104 cohort studies, many more than previous analyses of atrial fibrillation restricted to subpopulations. There were, however, some important limitations to consider. Firstly, despite our extensive search strategy, we could have missed relevant studies for inclusion. The large number of studies in our analysis, however, made our results robust to the inclusion of any single study. It also provided us with the power to investigate whether the associations between atrial fibrillation and cardiovascular disease and death differed by important patient and study characteristics as well as to conduct detailed sensitivity analyses.
Secondly, we observed high levels of heterogeneity $\left(\mathrm{I}^{2}>70 \%\right)$ for all vascular outcomes except for chronic kidney disease. This was not unexpected and might be caused by differences in study designs, methodological characteristics, type of atrial fibrillation, use of secondary prevention (such as anticoagulation) among included studies, and the definition and ascertainment of endpoints. For instance, the criteria in well established prospective cohorts ${ }^{8}$ were comprehensively detailed, whereas the criteria and specific diagnostic codes used in analyses of administrative data were not consistently provided. ${ }^{51}$ Differences in the diagnostic codes used in administrative data could have contributed to the high heterogeneity in our study. Nonetheless, when we systematically and sequentially excluded individual studies until heterogeneity was moderate $\left(\mathrm{I}^{2}<50 \%\right)$, relative risk estimates for vascular outcomes were consistent and significant, suggesting that the high levels of heterogeneity were not inflating summary relative risk estimates. Thirdly, studies were classified as well adjusted if they adjusted for age, sex, baseline cardiovascular disease, and at least two cardiovascular risk factors. Even though more stringent criteria could be used, such as requiring studies to adjust for drugs and outcome specific risk factors (for example, adjustment for race for the outcome of chronic kidney disease), there will nonetheless be residual confounding in the estimates derived from observational studies. Accordingly, it is likely that there are other variables that contribute to the association between atrial fibrillation and our outcomes of interest, in addition to any possible causal disease specific effects. Fourthly, because of our strict selection criteria, we identified fewer than nine studies for some outcomes and were unable to conduct sensitivity analyses. This is particularly important for congestive heart failure because the relative and absolute risk estimates for incident congestive heart failure were the highest among the outcomes we examined. It is therefore noteworthy that four of the six studies ${ }^{24271101}$ we included in our meta-analysis for incident congestive heart failure were conducted in general population cohorts and accounted for $75 \%$ of the weight for the summary relative risk. Fifthly, studies that reported significant associations between atrial fibrillation and cardiovascular disease and death might be more likely to be published. We did not, however, observe evidence of publication bias for any outcome other than stroke. Finally, we lacked individual patient data, which would have allowed us to systematically adjust for patient characteristics. We did not, however, observe any interaction when we compared studies based on our risk of bias assessment.

\section{Implications for clinicians, policy makers, and} future research

The mechanism by which atrial fibrillation is associated with an increased risk of a range of different cardiovascular diseases is unclear. In the case of myocardial infarction, atrial fibrillation could contribute to demand infarction and the subsequent development of type 2 myocardial infarction. ${ }^{7}$ It is also possible that the 


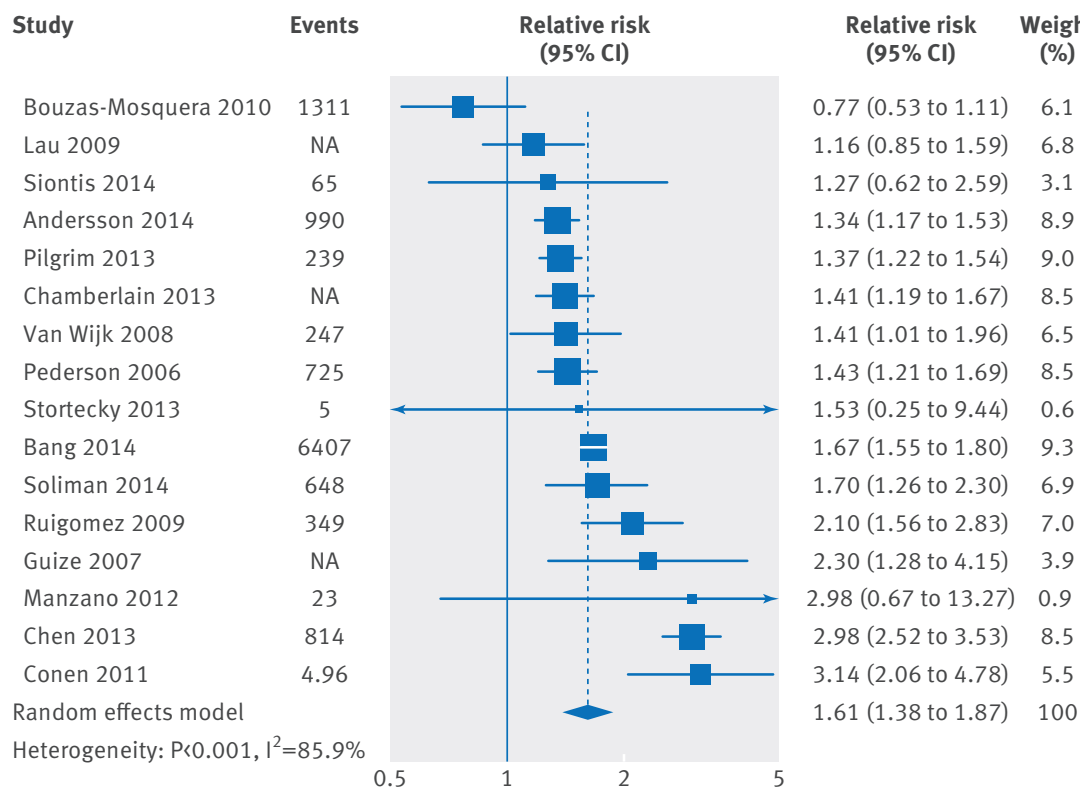

Fig 6 | Association between atrial fibrillation and ischaemic heart disease. NA=not available

association between atrial fibrillation and non-stroke cardiovascular disease is not causal. Considering our observation that atrial fibrillation is also associated with an increased risk of heart failure, sudden cardiac death, and chronic kidney disease (in addition to ischaemic heart disease), it seems likely that atrial fibrillation could be acting as a marker for shared underlying risk factors for cardiovascular disease. These include hypertension, which is diagnosed in up to $90 \%$ of patients with atrial fibrillation, as well as obesity, diabetes, and obstructive sleep apnoea. ${ }^{125126}$

Even though the associations we describe cannot indicate causality for the non-stroke outcomes, there is merit in developing clinical risk prediction models for outcomes such as congestive heart failure; particularly given our relative and absolute risk estimates. To date, three models have been developed with $\mathrm{C}$ statistics ranging from 0.7 to 0.84 , but none has been externally validated. ${ }^{127-129}$ Future models might also benefit from inclusion of non-invasive measures of cardiac function and assessments of novel biomarkers.

Finally, our study could have implications for the prioritisation of public health resources and the development of novel interventions for adults with atrial fibrillation. In particular, the development and testing of novel oral anticoagulants has been the principal focus of clinical care in atrial fibrillation, but recent studies have shown that these drugs reduce mortality related to stroke, with little reduction in mortality related to congestive heart failure and sudden cardiac death. ${ }^{123}$ Similarly, pharmacological control of atrial fibrillation and the restoration of sinus rhythm has shown no benefit over rate control for sudden cardiac death, ${ }^{130}$ worsening heart failure, ${ }^{131}$ or mortality. ${ }^{130}$ It could be that rhythm control treatments might not have been effective at treating atrial fibrillation or that the treatments resulted in additional side effects that outweighed the benefits of restoring sinus rhythm.
Alternatively, if atrial fibrillation is not the cause of these non-stroke outcomes, this could explain the absence of treatment benefit even when it is controlled.

Accordingly, reduction of the burden of non-stroke events in adults with atrial fibrillation would benefit from a focus on primary prevention and management of cardiovascular risk factors. Evidence based strategies in this regard include discussion of the concept of predicted cardiovascular risk with patients and calculation of their cardiovascular age. ${ }^{132}$ Regular updates should also be provided to patients after lifestyle changes and/ or pharmacotherapy have begun as a way to encourage further progress. ${ }^{132}$

In conclusion, atrial fibrillation is associated with cardiovascular and renal events, including cardiovascular mortality, major cardiovascular events, heart failure, ischaemic heart disease, chronic kidney disease, and sudden cardiac death, as well as stroke and all cause mortality. The relative and absolute risk increase associated with many of these events is greater than that of stroke. Interventions are needed to reduce the risk of non-stroke outcomes in adults with atrial fibrillation.

Contributors: $\mathrm{AO}$ and CAE conceived and designed the study, carried out the statistical analysis, had full access to all the data in the study, take responsibility for the integrity of the data and the accuracy of the data analysis, and are guarantors. All authors acquired data, analysed and interpreted data, drafted the manuscript, and critically revised the manuscript for important intellectual content.

Funding: This research received no specific grant from any funding agency in the public, commercial, or not-for-profit sectors. AO, CXW, $\mathrm{AJH}$, and CAE are supported by the Rhodes Trust

Competing interests: All authors have completed the ICMJE uniform disclosure form at www.icmje.org/coi_disclosure.pdf and declare: no support from any organisation for the submitted work; no financial relationships with any organisations that might have an interest in the submitted work in the previous three years; no other relationships or activities that could appear to have influenced the submitted work.

Ethical approval: Not required.

Data sharing: Data and code are available from the lead author on request.

Transparency: The lead authors affirm that the manuscript is an honest, accurate, and transparent account of the study being reported; that no important aspects of the study have been omitted; and that any discrepancies from the study as planned (and, if relevant, registered) have been explained.

This is an Open Access article distributed in accordance with the Creative Commons Attribution Non Commercial (CC BY-NC 3.0) license, which permits others to distribute, remix, adapt, build upon this work non-commercially, and license their derivative works on different terms, provided the original work is properly cited and the use is non-commercial. See: http://creativecommons.org/licenses/ by-nc/3.0/.

1 Chugh SS, Havmoeller R, Narayanan K, et al. Worldwide epidemiology of atrial fibrillation: a Global Burden of Disease 2010 Study. Circulation 2014:129:837-47. doi:10.1161/ CIRCULATIONAHA.113.005119.

2 Conen D, Chae CU, Glynn RJ, et al. Risk of death and cardiovascular events in initially healthy women with new-onset atrial fibrillation. JAMA 2011;305:2080-7. doi:10.1001/jama.2011.659.

3 Thrall G, Lane D, Carroll D, Lip GY. Quality of life in patients with atrial fibrillation: a systematic review. Am J Med 2006;119:448.e1-19. doi:10.1016/j.amjmed.2005.10.057.

4 January CT, Wann LS, Alpert JS, et al. ACC/AHA Task Force Members. 2014 AHA/ACC/HRS guideline for the management of patients with atrial fibrillation: executive summary: a report of the American College of Cardiology/American Heart Association Task Force on practice guidelines and the Heart Rhythm Society. Circulation 2014;130:2071. 104. doi:10.1161/CIR.0000000000000040.

5 Ruff CT, Giugliano RP, Braunwald E, et al. Comparison of the efficacy and safety of new oral anticoagulants with warfarin in patients with atrial fibrillation: a meta-analysis of randomised trials. Lancet 2014:383:955-62. doi:10.1016/S0140-6736(13)62343-0. 
6 Hart RG, Pearce LA, Aguilar MI. Meta-analysis: antithrombotic therapy to prevent stroke in patients who have nonvalvular atrial fibrillation. Ann Intern Med 2007:146:857-67.

doi:10.7326/0003-4819-146-12-200706190-00007.

7 Soliman EZ, Lopez F, O'Neal WT, et al. Atrial Fibrillation and Risk of ST-Segment-Elevation Versus Non-ST-Segment-Elevation Myocardial Infarction: The Atherosclerosis Risk in Communities (ARIC) Study. Circulation 2015;131:1843-50. doi:10.1161/ CIRCULATIONAHA.114.014145.

8 Soliman EZ, Safford MM, Muntner P, et al. Atrial fibrillation and the risk of myocardial infarction. JAMA Intern Med 2014;174:107-14. doi:10.1001/jamainternmed.2013.11912

9 O'Neal WT, Sangal K, Zhang Z-M, Soliman EZ. Atrial fibrillation and incident myocardial infarction in the elderly. Clin Cardiol 2014;37:7505. doi:10.1002/clc.22339.

10 Bansal N, Fan D, Hsu CY, Ordonez JD, Marcus GM, Go AS. Incident atrial fibrillation and risk of end-stage renal disease in adults with chronic kidney disease. Circulation 2013;127:569-74. doi:10.1161/ CIRCULATIONAHA.112.123992.

11 Hamaguchi S, Yokoshiki H, Kinugawa S, et al. Japanese Cardiac Registry of Heart Failure in Cardiology Investigators. Effects of atrial fibrillation on long-term outcomes in patients hospitalized for heart failure in Japan: a report from the Japanese Cardiac Registry of Heart Failure in Cardiology (JCARE-CARD). Circ J 2009;73:2084-90. doi:10.1253/circj.CJ-09-0316.

12 Desai H, Aronow WS, Ahn C, et al. Risk factors for appropriate cardioverter-defibrillator shocks, inappropriate cardioverterdefibrillator shocks, and time to mortality in 549 patients with heart failure. Am J Cardiol 2010;105:1336-8. doi:10.1016/j. amjcard.2009.12.057.

13 Chen LY, Sotoodehnia N, Bůžková P, et al. Atrial fibrillation and the risk of sudden cardiac death: the atherosclerosis risk in communities study and cardiovascular health study. JAMA Intern Med 2013;173:2935. doi:10.1001/2013.jamainternmed.744.

14 Bouzas-Mosquera A, Peteiro J, Broullón FJ, et al. Effect of atrial fibrillation on outcome in patients with known or suspected coronary artery disease referred for exercise stress testing. Am J Cardiol 2010;105:1207-11. doi:10.1016/j.amjcard.2009.12.037.

15 Stroup DF, Berlin JA, Morton SC, et al. Meta-analysis of observational studies in epidemiology: a proposal for reporting. Meta-analysis Of Observational Studies in Epidemiology (MOOSE) group. JAMA 2000;283:2008-12. doi:10.1001/jama.283.15.2008.

16 Moher D, Liberati A, Tetzlaff J, Altman DG. PRISMA Group. Preferred reporting items for systematic reviews and meta-analyses: the PRISMA statement. Ann Intern Med 2009;151:264-9, W64. doi:10.7326/0003-4819-151-4-200908180-00135.

17 Wells GA, Shea B. OConnell D, et al. The Newcastle-Ottawa Scale (NOS) for assessing the quality of nonrandomised studies in meta-analyses. http://www.ohri.ca/programs/clinical_epidemiology/nosgen.pdf.

18 Mozaffarian D, Benjamin EJ, Go AS, et al. Heart Disease and Stroke Statistics-2015 Update: A Report From the American Heart Association. Circulation 2014;131;e29-322. doi:10.1161/ CIR.0000000000000152.

19 Centers for Disease Control and Prevention (CDC). NVSS - Mortality Data. cdc.gov. http://www.cdc.gov/nchs/nvss/deaths.htm.

20 Centers for Disease Control and Prevention (CDC). Chronic Kidney Disease (CKD) Surveillance Project. https://nccd.cdc.gov/ckd/.

21 Patsopoulos NA, Evangelou E, loannidis JPA. Sensitivity of between-study heterogeneity in meta-analysis: proposed metrics and empirical evaluation. Int J Epidemiol 2008;37:1148-57. doi:10.1093/ ije/dyn065.

22 Cochrane. Recommendations on testing for funnel plot asymmetry. handbook.cochrane.org. http://handbook.cochrane. org/chapter_10/10_4_3_1_recommendations_on_testing_for_ funnel plot asymmetry.htm.

23 Egger M, Davey Smith G, Schneider M, Minder C. Bias in meta-analysis detected by a simple, graphical test. BMJ 1997;315:629-34 doi:10.1136/bmi.315.7109.629.

24 Duval S, Tweedie R. Trim and fill: A simple funnel-plot-based method of testing and adjusting for publication bias in meta-analysis. Biometrics 2000;56:455-63. doi:10.1111/j.0006-341X.2000.00455.X.

25 Goldberg RJ, Seeley D, Becker RC, et al. Impact of atrial fibrillation on the in-hospital and long-term survival of patients with acute myocardial infarction: a community-wide perspective. Am Heart J 1990;119:996-1001. doi:10.1016/S0002-8703(05)80227-3.

26 Tveit A, Flonaes B, Aaser E, et al. No impact of atrial fibrillation on mortality risk in optimally treated heart failure patients. Clin Cardiol 2011:34:537-42. doi:10.1002/clc.20939.

27 Rauns $\varnothing$ J, Pedersen OD, Dominguez H, et al. EchoCardiography and Heart Outcome Study Investigators. Atrial fibrillation in heart failure is associated with an increased risk of death only in patients with ischaemic heart disease. Eur J Heart Fail 2010;12:692-7. doi:10.1093/ eurjhf/hfq052.

28 Køber L, Torp-Pedersen C, Gadsbøll N, Hildebrandt P, Høilund-Carlsen PF. Is digoxin an independent risk factor for long-term mortality after acute myocardial infarction?Eur Heart / 1994;15:382-8.
29 Pedersen OD, Søndergaard P, Nielsen T, et al. DIAMOND study group investigators. Atrial fibrillation, ischaemic heart disease, and the risk of death in patients with heart failure. Eur Heart J 2006;27:2866-70. doi:10.1093/eurheartj/ehl359.

30 Asanin M, Perunicic J, Mrdovic I, et al. Prognostic significance of new atrial fibrillation and its relation to heart failure following acute myocardial infarction. Eur J Heart Fail 2005;7:671-6. doi:10.1016/j. ejheart.2004.07.018

31 Oluleye OW, Rector TS, Win S, et al. History of atrial fibrillation as a risk factor in patients with heart failure and preserved ejection fraction. Circ Heart Fail 2014;7:960-6. doi:10.1161/ CIRCHEARTFAILURE.114.001523.

32 Bajaj NS, Bhatia V, Sanam K, et al. Impact of atrial fibrillation and heart failure, independent of each other and in combination, on mortality in community-dwelling older adults. Am J Cardiol 2014;114:909-13. doi:10.1016/j.amjcard.2014.05.045

33 Wolf PA, Mitchell JB, Baker CS, Kannel WB, D’Agostino RB. Impact of atrial fibrillation on mortality, stroke, and medical costs. Arch Intern Med 1998;158:229-34. doi:10.1001/archinte.158.3.229.

34 Wyse DG, Love JC, Yao Q, et al. Atrial fibrillation: a risk factor for increased mortality--an AVID registry analysis. J Interv Card Electrophysiol 2001;5:267-73. doi:10.1023/A:1011460631369.

35 Kaarisalo MM, Immonen-Räihä P, Marttila RJ, et al. Atrial fibrillation in older stroke patients: association with recurrence and mortality after first ischemic stroke. J Am Geriatr Soc 1997;45:1297-301. doi:10.1111/j.1532-5415.1997.tb02927.x.

36 McManus DD, Saczynski JS, Lessard D, et al. Recent trends in the incidence, treatment, and prognosis of patients with heart failure and atrial fibrillation (the Worcester Heart Failure Study). Am J Cardiol 2013;111:1460-5. doi:10.1016/j.amjcard.2013.01.298.

37 Saposnik G, Kapral MK, Liu Y, et al. Investigators of the Registry of the Canadian Stroke Network Stroke Outcomes Research Canada (SORCan) Working Group. IScore: a risk score to predict death early after hospitalization for an acute ischemic stroke. Circulation 2011;123:739-49. doi:10.1161/CIRCULATIONAHA.110.983353.

38 Saczynski JS, McManus D, Zhou Z, et al. Trends in atrial fibrillation complicating acute myocardial infarction. Am J Cardiol 2009;104:169 74. doi:10.1016/j.amjcard.2009.03.011.

39 Behar S, Zahavi Z, Goldbourt U, Reicher-Reiss H. SPRINT Study Group. Long-term prognosis of patients with paroxysmal atrial fibrillation complicating acute myocardial infarction. Eur Heart/1992;13:45-50.

40 Duncan A, Ludman P, Banya W, et al. Long-term outcomes after transcatheter aortic valve replacement in high-risk patients with severe aortic stenosis: the U.K. Transcatheter Aortic Valve Implantation Registry. JACC Cardiovasc Interv 2015;8:645-53. doi:10.1016/j.jcin.2015.01.009.

41 Køber L, Swedberg K, McMurray JJV, et al. Previously known and newly diagnosed atrial fibrillation: a major risk indicator after a myocardial infarction complicated by heart failure or left ventricular dysfunction. EurJ Heart Fail 2006;8:591-8. doi:10.1016/j.ejheart.2005.11.007.

42 Andersson T, Magnuson A, Bryngelsson I-L, et al. Gender-related differences in risk of cardiovascular morbidity and all-cause mortality in patients hospitalized with incident atrial fibrillation without concomitant diseases: a nationwide cohort study of 9519 patients. Int J Cardiol 2014:177:91-9. doi:10.1016/j.ijcard.2014.09.092.

43 Baldasseroni S, De Biase L, Fresco C, et al. Italian Network on Congestive Heart Failure. Cumulative effect of complete left bundle-branch block and chronic atrial fibrillation on 1-year mortality and hospitalization in patients with congestive heart failure. A report from the Italian network on congestive heart failure (in-CHF database). Eur Heart J 2002;23:1692-8. doi:10.1053/euhj.2001.3157.

44 Rathore SS, Berger AK, Weinfurt KP, et al. Acute myocardial infarction complicated by atrial fibrillation in the elderly: prevalence and outcomes. Circulation 2000;101:969-74. doi:10.1161/01. CIR.101.9.969.

45 Dries DL, Exner DV, Gersh BJ, Domanski MJ, Waclawiw MA, Stevenson LW. Atrial fibrillation is associated with an increased risk for mortality and heart failure progression in patients with asymptomatic and symptomatic left ventricular systolic dysfunction: a retrospective analysis of the SOLVD trials. Studies of Left Ventricular Dysfunction. J Am Coll Cardiol 1998;32:695-703. doi:10.1016/S0735-1097(98)00297-6.

46 Abbott KC, Reynolds JC, Taylor AJ, Agodoa LY. Hospitalized atrial fibrillation after renal transplantation in the United States. Am J Transplant 2003;3:471-6. doi:10.1034/j.1600-6143.2003.00071.x.

47 Kimura K, Minematsu K, Kazui S, Yamaguchi T. Japan Multicenter Stroke Investigators' Collaboration (J-MUSIC). Mortality and cause of death after hospital discharge in 10,981 patients with ischemic stroke and transient ischemic attack. Cerebrovasc Dis 2005;19:171-8. doi:10.1159/000083252

48 Lau DH, Huynh LT, Chew DP, Astley CM, Soman A, Sanders P. Prognostic impact of types of atrial fibrillation in acute coronary syndromes. Am J Cardiol 2009;104:1317-23. doi:10.1016/j. amjcard.2009.06.055.

49 Kammersgaard LP, Olsen TSOJ. Cardiovascular risk factors and 5-year mortality in the Copenhagen Stroke Study. Cerebrovasc Dis 2006;21:187-93. doi:10.1159/000090531. 
50 Henriksson KM, Farahmand B, Johansson S, Asberg S, Terént A, Edvardsson N. Survival after stroke--the impact of CHADS2 score and atrial fibrillation. Int / Cardiol 2010;141:18-23. doi:10.1016/i. ijcard.2008.11.122

51 Wasmer K, Unrath M, Köbe J, et al. Atrial fibrillation is a risk marker for worse in-hospital and long-term outcome in patients with peripheral artery disease. Int J Cardiol 2015;199:223-8. doi:10.1016/j. ijcard.2015.06.094.

52 van Wijk I, Koudstaal PJ, Kappelle LJ, van Gijn J, Gorter JW, Algra A. LiLAC Study Group. Long-term occurrence of death and cardiovascular events in patients with transient ischaemic attack or minor ischaemic stroke: comparison between arterial and cardiac source of the index event. J Neurol Neurosurg Psychiatry 2008;79:895-9. doi:10.1136/ jnnp.2007.133132.

53 Aronow WS, Ahn C, Kronzon I. Prognosis of congestive heart failure after prior myocardial infarction in older persons with atrial fibrillation versus sinus rhythm. Am / Cardiol 2001:87:224-5, A8-9.

54 Siontis KC, Geske JB, Ong K, Nishimura RA, Ommen SR, Gersh BJ. Atrial fibrillation in hypertrophic cardiomyopathy: prevalence, clinical correlations, and mortality in a large high-risk population. J Am Heart Assoc 2014;3:e001002. doi:10.1161/JAHA.114.001002.

55 Bilato C, Corti MC, Baggio G, et al. Prevalence, functional impact, and mortality of atrial fibrillation in an older Italian population (from the Pro.V.A. study). Am J Cardiol 2009;104:1092-7. doi:10.1016/j. amjcard.2009.05.058.

56 Bengtson LGS, Chen LY, Chamberlain AM, et al. Temporal trends in the occurrence and outcomes of atrial fibrillation in patients with acute myocardial infarction (from the Atherosclerosis Risk in Communities Surveillance Study). Am J Cardiol 2014;114:692-7. doi:10.1016/j. amjcard.2014.05.059.

57 Fu S, Liu T, Luo L, Ye P. Different types of atrial fibrillation, renal function, and mortality in elderly Chinese patients with coronary artery disease. Clin Interv Aging 2014;9:301-8. doi:10.2147/CIA.S55972.

58 Marini C, De Santis F, Sacco S, et al. Contribution of atrial fibrillation to incidence and outcome of ischemic stroke: results from a population-based study. Stroke 2005;36:1115-9. doi:10.1161/01. STR $0000166053.83476 .4 a$

59 Bang CN, Greve AM, Boman K, et al. Effect of lipid lowering on new-onset atrial fibrillation in patients with asymptomatic aortic stenosis: the Simvastatin and Ezetimibe in Aortic Stenosis (SEAS) study. Am Heart J 2012;163:690-6. doi:10.1016/j.ahj.2012.01.026.

60 Ahmed A, Thornton P, Perry GJ, Allman RM, DeLong JF. Impact of atria fibrillation on mortality and readmission in older adults hospitalized with heart failure. Eur J Heart Fail 2004;6:421-6. doi:10.1016/j. ejheart.2003.11.011.

61 Guize L, Thomas F, Bean K, Benetos A, Pannier B. [Atrial fibrillation: prevalence, risk factors and mortality in a large French population with 15 years of follow-up]. Bull Acad Natl Med 2007:191:791-803, discussion 803-5.

62 Saxena A, Dinh D, Dimitriou J, et al. Preoperative atrial fibrillation is an independent risk factor for mid-term mortality after concomitant aortic valve replacement and coronary artery bypass graft surgery. Interact Cardiovasc Thorac Surg 2013;16:488-94. doi:10.1093/icvts/ivs538.

63 Santini M, Gasparini M, Landolina M, et al. cardiological centers participating in ClinicalService Project. Device-detected atria tachyarrhythmias predict adverse outcome in real-world patients with implantable biventricular defibrillators. J Am Coll Cardiol 2011;57:16772. doi:10.1016/j.jacc.2010.08.624.

64 Wong CK, White HD, Wilcox RG, et al. New atrial fibrillation after acute myocardial infarction independently predicts death: the GUSTO-III experience. Am Heart / 2000;140:878-85. doi:10.1067/ mhi.2000.111108.

65 Kinjo K, Sato H, Sato H, et al. Osaka Acute Coronary Insufficiency Study (OACIS) Group. Prognostic significance of atrial fibrillation/atrial flutter in patients with acute myocardial infarction treated with percutaneous coronary intervention. Am J Cardiol 2003;92:1150-4. doi:10.1016/j.amjcard.2003.07.021

66 Chamberlain AM, Redfield MM, Alonso A, Weston SA, Roger VL. Atrial fibrillation and mortality in heart failure: a community study. Circ Heart Fail 2011;4:740-6. doi:10.1161/CIRCHEARTFAILURE.111.962688.

67 Bansal N, Fan D, Hsu C-Y, Ordonez JD, Go AS. Incident atrial fibrillation and risk of death in adults with chronic kidney disease. J Am Heart Assoc 2014;3:e001303. doi:10.1161/JAHA.114.001303.

68 Pilgrim T, Kalesan B, Zanchin T, et al. Impact of atrial fibrillation on clinical outcomes among patients with coronary artery disease undergoing revascularisation with drug-eluting stents. Eurolntervention 2013;8:1061-71. doi:10.4244/EIJV8I9A163.

69 Benjamin EJ, Wolf PA, D’Agostino RB, Silbershatz H, Kannel WB, Levy D. Impact of atrial fibrillation on the risk of death: the Framingham Heart Study. Circulation 1998;98:946-52. doi:10.1161/01. CIR.98.10.946.

70 Chopard R, Teiger E, Meneveau N, et al. FRANCE-2 Investigators. Baseline Characteristics and Prognostic Implications of Pre-Existing and New-Onset Atrial Fibrillation After Transcatheter Aortic Valve Implantation: Results From the FRANCE-2 Registry. JACC CardiovasC Interv 2015;8:1346-55. doi:10.1016/j.jcin.2015.06.010.
71 Stewart S, Hart CL, Hole DJ, McMurray JJ. A population-based study of the long-term risks associated with atrial fibrillation: 20-year follow-up of the Renfrew/Paisley study. Am I Med 2002;113:359-64. doi:10.1016/S0002-9343(02)01236-6.

72 Liu X, Xu G, Wu W, Zhang R, Yin Q, Zhu W. Subtypes and one-year survival of first-ever stroke in Chinese patients: The Nanjing Stroke Registry. Cerebrovasc Dis 2006;22:130-6. doi:10.1159/000093241.

73 Pizzetti F, Turazza FM, Franzosi MG, et al. GISSI-3 Investigators. Incidence and prognostic significance of atrial fibrillation in acute myocardial infarction: the GISSI-3 data. Heart 2001;86:527-32. doi:10.1136/heart.86.5.527.

74 Bogale N, Priori S, Cleland JGF, et al. Scientific Committee, National Coordinators, and Investigators. The European CRT Survey: 1 year (9-15 months) follow-up results. EurJ Heart Fail 2012;14:61-73. doi:10.1093/eurjhf/hfr158.

75 Jabre P, Jouven X, Adnet F, et al. Atrial fibrillation and death after myocardial infarction: a community study. Circulation 2011;123:2094100. doi:10.1161/CIRCULATIONAHA.110.990192.

76 Béjot Y, Ben Salem D, Osseby GV, et al. Epidemiology of ischemic stroke from atrial fibrillation in Dijon, France, from 1985 to 2006. Neurology 2009;72:346-53. doi:10.1212/01.wnl.0000341280.31919.bd.

77 Ohsawa M, Okayama A, Okamura T, et al. Mortality risk attributable to atrial fibrillation in middle-aged and elderly people in the Japanese general population: nineteen-year follow-up in NIPPON DATA80. Circ 2007;71:814-9. doi:10.1253/circj.71.814.

78 Bang CN, Gislason GH, Greve AM, et al. New-onset atrial fibrillation is associated with cardiovascular events leading to death in a first time myocardial infarction population of 89,703 patients with long-term follow-up: a nationwide study. J Am Heart Assoc 2014;3:e000382-2. doi:10.1161/JAHA.113.000382.

79 Stein KM, Mittal S, Gilliam FR, et al. Predictors of early mortality in implantable cardioverter-defibrillator recipients. Europace 2009;11:734-40. doi:10.1093/europace/eup055.

80 Lake FR, Cullen KJ, de Klerk NH, McCall MG, Rosman DL. Atria fibrillation and mortality in an elderly population. Aust N ZJ Med 1989;19:321-6. doi:10.1111/j.1445-5994.1989.tb00271.x.

81 Friberg J, Scharling H, Gadsbøll N, Truelsen T, Jensen GB. Copenhagen City Heart Study. Comparison of the impact of atrial fibrillation on the risk of stroke and cardiovascular death in women versus men (The Copenhagen City Heart Study). Am J Cardiol 2004;94:889-94. doi:10.1016/i.amjcard.2004.06.023.

82 Stortecky S, Buellesfeld L, Wenaweser P, et al. Atrial fibrillation and aortic stenosis: impact on clinical outcomes among patients undergoing transcatheter aortic valve implantation. Circ Cardiovasc Interv 2013;6:77-84. doi:10.1161/CIRCINTERVENTIONS.112.000124.

83 Torres M, Rocha S, Marques J, et al. Impact of atrial fibrillation in acute coronary syndromes. Rev Port Cardiol 2008;27:1407-18.

84 Sakata K, Kurihara H, Iwamori K, et al. Clinical and prognostic significance of atrial fibrillation in acute myocardial infarction. Am J Cardiol 1997;80:1522-7. doi:10.1016/S0002-9149(97)00746-7.

85 Pedersen OD, Abildstrøm SZ, Ottesen MM, et al. TRACE Study Investigators. Increased risk of sudden and non-sudden cardiovascular death in patients with atrial fibrillation/flutter following acute myocardial infarction. Eur Heart / 2006;27:290-5. doi:10.1093/eurheartj/ehi629.

86 Olsson LG, Swedberg K, Ducharme A, et al. CHARM Investigators. Atrial fibrillation and risk of clinical events in chronic heart failure with and without left ventricular systolic dysfunction: results from the Candesartan in Heart failure-Assessment of Reduction in Mortality and morbidity (CHARM) program. J Am Coll Cardiol 2006;47:19972004. doi:10.1016/j.jacc.2006.01.060

87 Lau K-K, Wong Y-K, Teo K-C, et al. Stroke patients with a past history of cancer are at increased risk of recurrent stroke and cardiovascular mortality. PLoS One 2014;9:e88283. doi:10.1371/journal.pone.0088283.

88 Manzano JJF, De Silva DA, Pascual JLR, Chang HM, Wong MC, Chen CP. Associations of ankle-brachial index (ABI) with cerebral arterial disease and vascular events following ischemic stroke. Atherosclerosis 2012;223:219-22. doi:10.1016/j. atherosclerosis.2012.04.009.

89 Hippisley-Cox J, Coupland C, Robson J, Brindle P. Derivation, validation, and evaluation of a new QRISK model to estimate lifetime risk of cardiovascular disease: cohort study using QResearch database. BM/2010:341:c6624 doi:10.1136/bmi.c6624.

90 Ruff CT, Bhatt DL, Steg PG, et al. REACH Registry Investigators. Long-term cardiovascular outcomes in patients with atrial fibrillation and atherothrombosis in the REACH Registry. Int / Cardiol 2014:170:413-8. doi:10.1016/j.ijcard.2013.11.030.

91 Wetmore JB, Ellerbeck EF, Mahnken JD, et al. Atrial fibrillation and risk of stroke in dialysis patients. Ann Epidemiol 2013;23:112-8. doi:10.1016/j.annepidem.2012.12.011.

92 Simons LA, McCallum J, Friedlander Y, Simons J. Risk factors for ischemic stroke: Dubbo Study of the elderly. Stroke 1998;29:1341-6. doi:10.1161/01.STR.29.7.1341.

93 Sampson UK, Pfeffer MA, McMurray JJV, Lokhnygina Y, White HD, Solomon SD. VALIANT Trial Investigators. Predictors of stroke in high-risk patients after acute myocardial infarction: insights from the VALIANT Trial. Eur Heart / 2007:28:685-91. doi:10.1093/eurheartj/ehl197. 
94 Hippisley-Cox J, Coupland C, Brindle P. Derivation and validation of QStroke score for predicting risk of ischaemic stroke in primary care and comparison with other risk scores: a prospective open cohort study. BMJ 2013;346:f2573. doi:10.1136/bmj.f2573.

95 Biblo LA, Yuan Z, Quan KJ, Mackall JA, Rimm AA. Risk of stroke in patients with atrial flutter. Am / Cardiol 2001;87:346-9, A9.

96 Hillen T, Coshall C, Tilling K, Rudd AG, McGovern R, Wolfe CD. South London Stroke Register. Cause of stroke recurrence is multifactorial: patterns, risk factors, and outcomes of stroke recurrence in the South London Stroke Register. Stroke 2003:34:1457-63. doi:10.1161/01. STR.0000072985.24967.7F

97 Burke JF, Stulc JL, Skolarus LE, Sears ED, Zahuranec DB, Morgenstern LB. Traumatic brain injury may be an independent risk factor for stroke. Neurology 2013;81:33-9. doi:10.1212 WNL.0b013e318297eecf.

98 Soliman EZ, Howard G, Meschia JF, et al. Self-reported atrial fibrillation and risk of stroke in the Reasons for Geographic and Racial Differences in Stroke (REGARDS) study. Stroke 2011;42:2950-3. doi:10.1161/STROKEAHA.111.621367.

99 Rodgers H, Greenaway J, Davies T, Wood R, Steen N, Thomson R. Risk factors for first-ever stroke in older people in the north East of England: a population-based study. Stroke 2004;35:7-11. doi:10.1161/01.STR.0000106914.60740.78.

100 Chao T-F, Liu C-J, Chen S-J, et al. Atrial fibrillation and the risk of ischemic stroke: does it still matter in patients with a CHA2DS2-VASc score of 0 or 1?Stroke 2012;43:2551-5. doi:10.1161/ STROKEAHA.112.667865.

101 Ruigómez A, Johansson S, Wallander M-A, Edvardsson N, García Rodríguez LA. Risk of cardiovascular and cerebrovascular events after atrial fibrillation diagnosis. Int / Cardiol 2009;136:186-92. doi:10.1016/j.ijcard.2008.04.050

102 Bishara R, Telman G, Bahouth F, Lessick J, Aronson D. Transient atrial fibrillation and risk of stroke after acute myocardial infarction. Thromb Haemost 2011:106:877-84 doi:10.1160/TH11-05-0343.

103 Aronow WS, Ahn C, Kronzon I, Gutstein H. Association of left ventricular hypertrophy and chronic atrial fibrillation with the incidence of new thromboembolic stroke in 2,384 older persons. Am J Cardiol 1999;84:468-9, A9.

104 Aronow WS, Ahn C, Gutstein H. Prevalence of atrial fibrillation and association of atrial fibrillation with prior and new thromboembolic stroke in older patients. J Am Geriatr Soc 1996;44:521-3. doi:10.1111/j.1532-5415.1996.tb01436.x

105 Xu G, Liu X, Wu W, Zhang R, Yin Q. Recurrence after ischemic stroke in chinese patients: impact of uncontrolled modifiable risk factors. Cerebrovasc Dis 2007;23:117-20. doi:10.1159/000097047.

106 Wolf PA, Abbott RD, Kannel WB. Atrial fibrillation: a major contributor to stroke in the elderly. The Framingham Study. Arch Intern Med 1987:147:1561-4. doi:10.1001/archinte.1987.00370090041008

107 Iwahana $\mathrm{H}$, Ishikawa S, Ishikawa J, et al. Atrial fibrillation is a major risk factor for stroke, especially in women: the Jichi Medical School cohort study. J Epidemiol 2011;21:95-101. doi:10.2188/jea.JE20090149.

108 Wang T-J, Keller JJ, Sheu J-J, Lin HC. A 3-year follow-up study on the risk of stroke among patients with conjunctival haemorrhage. Acta Ophthalmol 2013;91:226-30. doi:10.1111/j.1755-3768.2011.02359.x.

109 Hermann DM, Gronewold J, Lehmann N, et al; Heinz Nixdorf Recall Study Investigative Group. Coronary artery calcification is an independent stroke predictor in the general population. Stroke 2013:44:1008-13. doi:10.1161/STROKEAHA.111.678078.

110 Kamel H, Johnson DR, Hegde M, et al. Detection of atrial fibrillation after stroke and the risk of recurrent stroke. / Stroke Cerebrovasc Dis 2012;21:726-31. doi:10.1016/j.jstrokecerebrovasdis.2011.03.008.

111 Nakayama T, Date C, Yokoyama T, Yoshiike N, Yamaguchi M, Tanaka H. A 15.5-year follow-up study of stroke in a Japanese provincial city. The Shibata Study. Stroke 1997;28:45-52. doi:10.1161/01.STR.28.1.45.

112 Feng S-J, Liu M, Li W-Z, Li W, Zhang SH. [A prospective study of stroke recurrence and the risk factors]. Nan Fang Yi Ke Da Xue Xue Bao 2009;29:983-5.

113 Ruel M, Masters RG, Rubens FD, et al. Late incidence and determinants of stroke after aortic and mitral valve replacement. Ann Thorac Surg 2004;78:77-83, discussion 83-4. doi:10.1016/j.athoracsur.2003.12.058.

114 Marijon E, Trinquart L, Otmani A, et al. Evaluation Médico-Economique du Défibrillateur Automatique Implantable (EVADEF) Investigators. Competing risk analysis of cause-specific mortality in patients with an implantable cardioverter-defibrillator: The EVADEF cohort study. Am Heart/2009;157:391-397.e1. doi:10.1016/i.ahj.2008.09.023.

115 Genovesi S, Valsecchi MG, Rossi E, et al. Sudden death and associated factors in a historical cohort of chronic haemodialysis patients. Nephrol Dial Transplant 2009:24:2529-36. doi:10.1093/ndt/gfp104.
116 Okin PM, Bang CN, Wachtell K, et al. Relationship of sudden cardiac death to new-onset atrial fibrillation in hypertensive patients with left ventricular hypertrophy. Circ Arrhythm Electrophysiol 2013;6:243-51. doi:10.1161/CIRCEP.112.977777.

117 Smit MD, Van Dessel PFHM, Nieuwland W, et al. Right ventricular pacing and the risk of heart failure in implantable cardioverterdefibrillator patients. Heart Rhythm 2006;3:1397-403. doi:10.1016/j. hrthm.2006.08.006

118 Ruel M, Kapila V, Price J, Kulik A, Burwash IG, Mesana TG. Natural history and predictors of outcome in patients with concomitant functional mitral regurgitation at the time of aortic valve replacement. Circulation 2006;114(Suppl):1541-6. doi:10.1161/ CIRCULATIONAHA.105.000976.

119 O’Neal WT, Tanner RM, Efird JT, et al. Atrial fibrillation and incident end-stage renal disease: The REasons for Geographic And Racial Differences in Stroke (REGARDS) study. Int J Cardiol 2015;185:219-23. doi:10.1016/j.ijcard.2015.03.104.

120 Watanabe H, Watanabe T, Sasaki S, Nagai K, Roden DM, Aizawa Y. Close bidirectional relationship between chronic kidney disease and atrial fibrillation: the Niigata preventive medicine study. Am HeartJ 2009;158:629-36. doi:10.1016/j.ahj.2009.06.031.

121 Chang C-J, Chen Y-T, Liu C-S, et al. Atrial Fibrillation Increases the Risk of Peripheral Arterial Disease With Relative Complications and Mortality: A Population-Based Cohort Study. Medicine (Baltimore) 2016;95:e3002. doi:10.1097/MD.0000000000003002.

122 Piccini JP, Hammill BG, Sinner MF, et al. Clinical course of atrial fibrillation in older adults: the importance of cardiovascular events beyond stroke. Eur Heart J 2014;35:250-6. doi:10.1093/eurheartj/ eht483.

123 Marijon E, Le Heuzey J-Y, Connolly S, et al. RE-LY Investigators. Causes of death and influencing factors in patients with atrial fibrillation: a competing-risk analysis from the randomized evaluation of long-term anticoagulant therapy study. Circulation 2013;128:2192-201. doi:10.1161/CIRCULATIONAHA.112.000491.

124 Cheng M, Lu X, Huang J, Zhang J, Zhang S, Gu D. The prognostic significance of atrial fibrillation in heart failure with a preserved and reduced left ventricular function: insights from a meta-analysis. Eur 」 Heart Fail 2014;16:1317-22. doi:10.1002/ejhf.187.

125 Manolis AJ, Rosei EA, Coca A, et al. Hypertension and atrial fibrillation: diagnostic approach, prevention and treatment. Position paper of the Working Group 'Hypertension Arrhythmias and Thrombosis' of the European Society of Hypertension. J Hypertens 2012;30:239-52. doi:10.1097/HJH.Ob013e32834f03bf.

126 Leong DP, Eikelboom JW, Healey IS, Connolly SJ. Atrial fibrillation is associated with increased mortality: causation or association?Eur Heart) 2013;34:1027-30. doi:10.1093/eurheartj/eht044.

127 Suzuki S, Sagara K, Otsuka T, et al. A new scoring system for evaluating the risk of heart failure events in lapanese patients with atrial fibrillation. Am J Cardiol 2012;110:678-82. doi:10.1016/j. amjcard.2012.04.049.

128 Potpara TS, Polovina MM, Licina MM, Marinkovic JM, Lip GY. Predictors and prognostic implications of incident heart failure following the first diagnosis of atrial fibrillation in patients with structurally normal hearts: the Belgrade Atrial Fibrillation Study. Eur J Heart Fail 2013:15:415-24. doi:10.1093/eurihf/hft004.

129 Schnabel RB, Rienstra M, Sullivan LM, et al. Risk assessment for incident heart failure in individuals with atrial fibrillation. Eur J Heart Fail 2013:15:843-9. doi:10.1093/eurihf/hft041.

130 Caldeira D, David C, Sampaio C. Rate versus rhythm control in atria fibrillation and clinical outcomes: updated systematic review and meta-analysis of randomized controlled trials. Arch Cardiovasc Dis 2012:105:226-38. doi:10.1016/i.acvd.2011.11.005

131 Roy D, Talajic M, Nattel S, et al. Atrial Fibrillation and Congestive Heart Failure Investigators. Rhythm control versus rate control for atrial fibrillation and heart failure. N Engl J Med 2008;358:2667-77. doi:10.1056/NEJMoa0708789.

132 Grover SA, Lowensteyn I, Joseph L, et al. Cardiovascular Health Evaluation to Improve Compliance and Knowledge Among Uninformed Patients (CHECK-UP) Study Group. Patient knowledge of coronary risk profile improves the effectiveness of dyslipidemia therapy: the CHECK-UP study: a randomized controlled trial. Arch Intern Med 2007;167:2296-303. doi:10.1001/archinte.167.21.2296.

(C) BMJ Publishing Group Ltd 2016

Appendix: Search strategy, supplementary tables A-L, supplementary figures $\mathrm{A}-\mathrm{Q}$, web references 